Vol. 35 (1), 2017 (ISSN 0254-9247)

\title{
Estilos fenomenológicos de evocación de recuerdos autobiográficos en individuos con depresión mayor
}

\author{
María Lolich $^{1}$, Susana Azzollini ${ }^{2}$ \\ Universidad de Buenos Aires - Argentina; Consejo Nacional de Investigaciones \\ Cientificas y Técnicas (CONICET)
}

La evocación de recuerdos autobiográficos se caracteriza por presentar distintos componentes fenomenológicos. Dada la ausencia de trabajos previos realizados en poblaciones hispanoparlantes, se realizaron 34 entrevistas en profundidad a individuos con y sin trastorno depresivo mayor de la ciudad de Buenos Aires (Argentina). Fueron explorados los componentes fenomenológicos presentes en la evocación de recuerdos autobiográficos significativos. Los datos fueron analizados cualitativamente por medio de la Teoría Fundamentada en los Hechos. Durante el análisis descriptivo, se detectaron siete categorías fenomenológicas emergentes del discurso. Del análisis axial y selectivo fueron identificados dos ejes discursivos: retórico-proposicional y especificidad-generalidad. Las implicancias, en la regulación afectiva, derivadas de la asunción de un estilo amodal o multimodal de procesamiento de información autobiográfica merecen mayor atención.

Palabras clave: fenomenología, memoria autobiográfica, depresión, multimodal, amodal.

\section{Phenomenological retrieval style of autobiographical memories in a sample of major depressed individuals}

Autobiographical memory retrieval implies different phenomenological features. Given the lack of previous work in Hispanic-speaking populations, 34 in depth interview were carried out in individuals with and without Major Depressive Disorder in Buenos Aires, Argentina. Phenomenological components during the evocation of autobiographical memories were explored. Data was qualitatively analyzed using Grounded Theory. During the descriptive analyses, seven phenomenological categories were detected as emerging from the discourse.

1 Doctora en Psicología, investigadora adjunta Conicet, profesora adjunta Universidad de Buenos Aires, Secretaria de CyT Fac. del Ejército (UNDEF). Dirección postal: Av. Rivadavia 6015, 6to. D. Cap. Fed. (1406), Argentina. Contacto: susana1060@yahoo.com.ar

2 Magíster en Psicología Cognitiva por la Universidad de Buenos Aires (Argentina) y becaria de Doctorado por el CONICET dentro del proyecto de investigación titulado: "Dimensiones fenomenológicas en la evocación de recuerdos autobiográficos significativos: perfil diferencial en individuos con y sin trastorno depresivo mayor" (2012-17). Dirección postal: Salguero 1612, 1ero B. Cap. Fed. (1425), Argentina. Contacto: lolichm@yahoo.com.ar 
The axial and selective analyses revealed two main discursive axles areas; rhetoric-propositional and specificity- generalized. The impact on affective regulation processes, derived from the assumption of an amodal or multimodal style of processing autobiographical information, merits further attention.

Keywords: phenomenology, autobiographical memory, depression, multimodal, amodal.

Estilos fenomenológicos de evocaçáo de memórias autobiográficas em indivíduos com depressáo maior

A evocação de memórias autobiográficas é caracterizada por diferentes componentes fenomenológicos. Dada a falta de trabalhos prévios sobre o tema em populaçóes de língua espanhola, 34 entrevistas em profundidade foram conduzidas em indivíduos com e sem transtorno depressivo maior na cidade de Buenos Aires (Argentina). Foram explorados os componentes fenomenológicos presentes na evocação de memórias autobiográficas significativas. Os dados foram analisados qualitativamente através da Teoria Fundamentada. Durante a análise descritiva, foram detectadas sete categorias fenomenológicas emergentes no discurso. Dos analises axial e seletivo foram identificados dois eixos discursivos: retórico-proposicional e especificidade-generalidade. As implicações, na regulação afetiva, decorrentes da assunção de um estilo amodal ou um estilo multimodal no processamento de informaçôes autobiográficas merecem mais atenção.

Palavras-chave: fenomenologia, memória autobiográfica, depressão, multimodal, amodal. 
Dentro de las ciencias cognitivas, se entiende a la memoria autobiográfica (MA) como aquella función responsable del registro, conservación y evocación de información personal por períodos prolongados de tiempo (Conway, 2005; Tulving, 2002;). La MA opera con representaciones de episodios de vida, los recuerdos autobiográficos (RsAs), los cuales posibilitan la reconstrucción, en el presente, de experiencias vitales previas. Los RsAs significativos, refieren a eventos de relevancia personal para los individuos (Denkova, Dolcos \& Dolcos, 2012; Schaefer \& Philippot, 2005). Así, se los ha caracterizado como recuerdos relativos a situaciones que marcan un antes y un después, experiencias de aprendizaje fuertemente vinculadas con la propia identidad o eventos que conforman hitos en el curso vital (Singer \& Salovey, 1993; Sutin, Costa, Wethington \& Eaton, 2010).

A diferencia de la memoria semántica, al evocar RsAs las personas son capaces no solo de generar narrativas sobre distintos episodios de vida sino también de precisar detalles fenomenológicos sobre los sucesos vividos (Tulving, 2002). Esto es, al evocar un recuerdo autobiográfico (RA) los individuos suelen referir una serie de imágenes, sonidos, aromas, una amplia variedad de emociones, e inclusive, la sensación de re-experimentación o de viajar atrás en el tiempo (Barsalou, 2008; Rubin, Schrauf \& Greenberg, 2003; Sutin \& Robins, 2007; Tulving, 2002). De esta manera, investigaciones realizadas en las últimas décadas han encontrado evidencias que sugieren que, durante la evocación de RsAs, participan áreas cerebrales vinculadas al procesamiento de información de tipo afectiva, visual, háptica, gustativa, olfativa, auditiva y kinestésica entre otras (Barsalou, 2008; Conway, 2001; Rubin, Schrauf \& Greenberg, 2003;). Al presente se proponen estilos de evocación característicos de acuerdo a la valencia emocional del recuerdo, la cantidad e intensidad de los componentes especificados, variables socio-demográficas, la tipología del recuerdo (significativo, traumático, 
exclusivo de la infancia temprana, etc.), antecedentes de enfermedades neurológicas o trastornos psiquiátricos (Rubin, Schraut \& Greenberg, 2003; Williams, Barnhofer, Crane, Herman, Raes, Watkins \& Dalgleish, 2007). Particularmente, la presencia de psicopatología afectiva incidiría en distintos aspectos del procesamiento mnémico pudiendo afectar la consolidación de nueva información, generar distorsión o bien alterar el acceso a la misma (Conway, 2001).

Si bien se dispone de una variedad de formas de conceptualizar los fenómenos depresivos, hoy en día comienza a tomar fuerza la concepción dimensional o espectral. Por su parte, el trastorno depresivo mayor (TDM) implica la presencia de un estado de ánimo significativamente disminuido la pérdida de interés o de placer, por al menos dos semanas (American Psychological Association, 2013). Además, se presentan otro conjunto amplio de síntomas que a grandes rasgos pueden ser abordados como de tipo anímicos-cognitivos y somáticos (Leiderman, Vázquez, Lolich \& Baldessarini, 2012). Si bien clásicamente se concibió a las alteraciones depresivas a partir de una serie de síntomas afectivos, la modalidad de procesamiento de la información ocupa un rol cada vez más preponderante en este tipo de patologías (Watkins \& Teasdale, 2004; Watkins, 2008; Werner-Seidler \& Moulds, 2011a). Se ha descripto particularmente la tendencia hacia un procesamiento analítico, sobregeneralizado de la información. Es más, la instauración de dicha modalidad de procesamiento se ha vinculado al curso clínico y a la gravedad de este tipo de cuadros (Watkins \& Teasdale, 2004).

La MA se encuentra en estrecha relación con los procesos de la afectividad y con la evaluación del sí mismo (Conway, 2005; Montebarocci, Luchetti \& Singer, 2014; Mosoco, 2014; Werner-Seidler \& Moulds, 2011b). Tal es así que, durante un TDM, la MA suele verse notoriamente afectada (Conway, 2005; Watkins \& Teasdale, 2004). $\mathrm{Al}$ presente, investigadores en Europa y en los Estados Unidos proponen perfiles fenomenológicos de evocación distintivos en personas que presentan un TDM (Sumner, Griffith \& Mineka, 2010; WernerSeidler \& Moulds, 2011a). 
Por un lado, clásicamente se ha estudiado la tendencia de los individuos con depresión a evocar recuerdos de valencia negativa (Cláudio, Noronha \& Balola, 2014; Conway, 2001; Werner-Seidler \& Moulds, 2011a). Por otro lado, también se ha abordado el fenómeno de sobregeneralización de los RsAs (Williams et al., 2007). Esto es, se ha encontrado que, al presentárseles distintas palabras clave preseleccionadas (no necesariamente significativas en la historia biográfica), los individuos con depresión tienden a recordar, antes que un recuerdo particular, una serie difusa de eventos similares reunidos en una categoría global. Los mismos suelen evocarse con pocos detalles, con baja intensidad y con características inespecíficas. Presentarían, por tanto, déficits para acceder a eventos puntuales de vida, los llamados recuerdos específicos (Conway, 2001; Sumner, Griffith \& Mineka, 2010; Williams et al., 2007). Este tipo de procesamiento mnémico ocurriría tanto para con recuerdos agradables como desagradables. Si bien continúa siendo controversial, la mayoría de los estudios concuerdan en que los recuerdos positivos son evocados con menor frecuencia y son, además, los más sobregeneralizados (Conway, 2005; Sutin \& Robins, 2007; Williams et al., 2007). Además, otros estudios (e.g. Kuyken \& Moulds, 2009) han reportado que este grupo clínico suele evocar sus recuerdos desde una perspectiva de tercera persona, como si fueran observadores externos, antes que volver a experimentar las imágenes desde la perspectiva original.

Conocer las características del perfil fenomenológico de evocación de RsAs en individuos afectados por un TDM resulta de relevancia. En primer lugar, evocar de modo específico RsAs positivos suele ser una estrategia frecuentemente utilizada en poblaciones sanas para mejorar el estado de ánimo ante situaciones de estrés. Los individuos con TDM presentan, en cambio, dificultades para hacer uso de dicho recurso (Werner-Seidler \& Moulds, 2011b). Por otro lado, distintos autores han reportado que la evocación de modo generalizada de RsAs negativos, si bien puede resultar beneficiosa en primera instancia como mecanismo para evitar recuerdos displacenteros, conllevaría a mediano plazo consecuencias contraprudenciales en el estado de anímico (Williams et al., 
2007). En cambio, el poder identificar los perfiles fenomenológicos de evocación de los individuos con TDM y favorecer la asunción de un estilo más concreto de evocación ha mostrado efectos positivos en abordajes derivados del Mindfulness y de la imaginería cognitiva (Crawley, 2014; Werner-Seidler \& Moulds, 2011b). Dichas intervenciones clínicas buscan favorecer la asunción de modalidades alternativas de procesamiento de la información, por ejemplo mediante una evocación especifica de RsAs, comenzando a mostrarse como una vía psicoterapéutica idónea en el abordaje de trastornos afectivos y de la ansiedad (Watkins, Moberly \& Moulds, 2008; Watkins, 2008; Werner-Seidler \& Moulds, 2011b).

Los RsAs suelen emerger, independientemente de la escuela desde la que se trabaje, en todo proceso psicoterapéutico. La promoción de una modalidad cognitiva de procesamiento específico de RsAs puede ser un recurso de relevancia a ser considerado en la práctica clínica (Watkins et al., 2008; Werner-Seidler \& Moulds, 2011b). Conocer en profundidad cuáles son las dimensiones fenomenológicas de evocación más habituales en pacientes con depresión así como las características particulares que asumen dichas evocaciones en individuos sanos, puede resultar de gran utilidad para el abordaje de los trastornos depresivos.

Llamativamente y hasta donde se tiene conocimiento, no se dispone de estudios en poblaciones hispanoparlantes que hayan indagado en las dimensiones fenomenológicas de los RsAs en personas con y sin TDM (Lolich \& Azzollini, 2012). Considerando los posibles vínculos entre los RsAs y el contexto sociocultural a partir del cual se conforman (Dritschel, Kao, Astell, Neufeind \& Lai, 2011) y, teniendo en cuenta el rol de los RsAs en la concepción del sí-mismo y en los procesos de regulación emocional (Bluck \& Habermas, 2005; Cláudio, Noronha \& Balola, 2014; Conway, 2005), investigar los estilos fenomenológicos de evocación en individuos con y sin TDM se considera necesario.

El presente trabajo tuvo como objetivo explorar los componentes fenomenológicos de evocación de RsAs significativos en personas con y sin TDM residentes en la ciudad de Buenos Aires. 


\section{Método}

Este trabajo se enmarcó como un estudio exploratorio, observacional de tipo transversal, bajo un abordaje de investigación social-cualitativa (Cornejo \& Salas, 2011). Considerando el objetivo exploratorio y el énfasis otorgado a la subjetividad de los participantes como fuente de información, el estudio se adscribió al paradigma interpretativo (Krause, 1995). Desde el mismo, se postula que los diferentes ámbitos de la realidad, y particularmente los fenómenos humanos, son dependientes de los significados que las personas le atribuyen a los mismos. En consonancia, el presente estudio se realizó bajo el enfoque de la Teoría Fundamentada en los Hechos. Sobre la base de la misma, se procura construir modelos teóricos explicativos de los fenómenos psicosociales con el objetivo de que estos puedan ser utilizados como un sustento de prácticas e intervenciones a ser aplicadas en el terreno del cual fueron enunciadas (Strauss \& Corbin, 1998).

\section{Participantes}

Un total de 34 individuos adultos con y sin TDM residentes en la ciudad de Buenos Aires (Argentina) participaron de entrevistas en profundidad (ver Tabla 1). El número muestral estuvo determinado por el criterio de saturación de la información. Esto es, se interrumpió la recolección de datos cuando las categorías y su contenido asociado dejaron de mostrar nuevas relaciones y propiedades emergentes (Strauss \& Corbin, 1998). 


\section{Tabla 1}

Caracteristicas sociodemográficas de los participantes

\begin{tabular}{|c|c|c|c|c|}
\hline & $\begin{array}{c}\text { Total } \\
\text { muestra }\end{array}$ & $\begin{array}{c}\text { Grupo con } \\
\text { TDM }\end{array}$ & $\begin{array}{l}\text { Grupo sin } \\
\text { TDM }\end{array}$ & $p$ \\
\hline N (\%) & $34(100)$ & $16(47.1)$ & $18(52.9)$ & \\
\hline Mujeres [n (\%)] & $24(70.6)$ & $12(75.0)$ & $12(66.7)$ & $.44^{\mathrm{a}}$ \\
\hline Edad $\left[\right.$ Mediana $\left.\left(\mathrm{RI}^{*}\right)\right]$ & $47.5(14.2)$ & $48.5(12.7)$ & $46.5(24.5)$ & $.73^{b}$ \\
\hline Nivel de estudios [n (\%)] & & & & $.80^{c}$ \\
\hline Secundaria incompleta & $13(38.2)$ & $7(43.8)$ & $6(33.3)$ & \\
\hline Universitario incompleto & $11(32.4)$ & $5(31.3)$ & $6(33.3)$ & \\
\hline Universitario completo & $10(29.4)$ & $4(25.0)$ & $6(33.3)$ & \\
\hline Estado civil [n (\%)] & & & & $.41^{c}$ \\
\hline Soltero & $10(29.4)$ & $4(25.0)$ & $6(33.3)$ & \\
\hline En pareja & $13(38.2)$ & $5(31.1)$ & $8(44.4)$ & \\
\hline Divorciado & $11(32.4)$ & $7(43.8)$ & $4(22.2)$ & \\
\hline Puntaje Total IDB [Mediana (RI)] & $8.5(19)$ & $20.5(14)$ & $1.0(1)$ & $.00^{\mathrm{b}}$ \\
\hline \multicolumn{5}{|l|}{ Categorías Sintomatológicas $[\mathrm{n}(\%)]$} \\
\hline $\operatorname{Sin} \operatorname{SDCS}^{* *}(<13)$ & $18(52.9)$ & $0(0)$ & $18(100)$ & \\
\hline SDCS Leve $(\leq 13)$ & $3(8.8)$ & $3(18.8)$ & $0(0)$ & \\
\hline Depresión Leve-Moderada $(\leq 17)$ & $5(14.7)$ & $5(31.3)$ & $0(0)$ & \\
\hline Depresión Moderada $(\leq 21)$ & $3(8.8)$ & $3(18.8)$ & $0(0)$ & \\
\hline Depresión Severa( $\leq 31)$ & $5(14.7)$ & $5(31.3)$ & $0(0)$ & \\
\hline
\end{tabular}

Nota. * Rango Intercuartil; ${ }^{* *}$ Sintomatología depresiva clínicamente significativa; a Prueba Exacta de Fischer; ${ }^{\mathrm{b}}$ Prueba de la Mediana; ${ }^{\mathrm{c}}$ Prueba Chi-cuadrado

Fueron incluidos un total de 16 individuos con TDM entre 18-65 años con un diagnostico primario de depresión mayor de acuerdo a los criterios establecidos en el DSM-IV-TR (American Psychiatric Association-TR, 2000) y cuyo puntaje en el Inventario de Depresión de Beck (IDB) fuera igual o mayor a 13 (ver Tabla 1). Si bien el n de la muestra es pequeño y la amplitud etaria es amplia, se buscó contemplar la heterogeneidad estructural del objeto de estudio en pos de asegurar 
la diversidad de matices que el tipo de abordaje cualitativo pretende (Mejía Navarrete, 2000).

El grupo control estuvo conformado por un total de 18 participantes de la población general de similares características sociodemográficas. Se invitó a participar a los individuos que residían en las comunas donde se encontraban ubicadas las instituciones de salud de donde fueron reclutados los individuos con TDM. Fueron incluidos aquellos participantes entre 18-65 años que refirieron la ausencia de antecedentes previos o actuales de trastornos afectivos y que presentaran un puntaje menor a 13 en el IDB.

En ambos grupos fueron excluidos aquellos individuos que presentaron antecedentes previos o actuales de otros trastornos psiquiátricos, retraso mental u otras enfermedades médicas de consideración que pudieran afectar el desempeño cognitivo y por tanto las respuestas brindadas durante la evaluación. Además, aun cuando los participantes cumplieran con los criterios de inclusión, se excluyó a aquellos individuos que se negaron a firmar el consentimiento informado o bien a aquellos individuos que una vez comenzada la evaluación quisieron darla por terminada antes de tiempo $\left(\mathrm{n}_{\text {TDM }}=1\right)$.

\section{Instrumentos}

Recuerdos autobiográficos. Para explorar los componentes fenomenológicos prevalecientes en RsAs significativos se llevaron a cabo entrevistas semiestructuradas en profundidad. Se utilizó, como eje de las mismas, distintos componentes fenomenológicos mencionados en la literatura (imágenes, olores y sonidos) así como aquellas características identificadas de un primer estudio piloto llevado a cabo en el ańo 2010. Un resumen de las preguntas de la entrevista se puede encontrar en el Anexo II. Las entrevistas tuvieron una duración aproximada de 60 minutos y fueron realizadas en consultorios individuales.

Depresión. De forma complementaria al diagnóstico médico, fue utilizado el Inventario de Depresión de Beck I (Beck, 1996) para evaluar la presencia (puntaje $\geq 13$ ) y severidad de la sintomatología depresiva clínicamente significativa. Se empleó la versión traducida, estandarizada 
y adaptada a la población Argentina (Bonicatto, 1998; Lasa, AyusoMateos, Vásquez-Barquero, Díez-Manrique \& Dowrick, 2000). El IDB es un inventario autoadministrable, incluye 21 ítems de síntomas depresivos; cada reactivo incluye a su vez 4 opciones de respuesta a las que les corresponde un puntaje de 0 a 3 de acuerdo a la gravedad del síntoma (puntaje máximo 63). El puntaje final se obtiene de la suma directa de los puntajes correspondientes a cada ítem. La adaptación local posee propiedades psicométricas satisfactorias entre ellas; una sensibilidad del $100 \%$ y especificidad del $99 \%$, con un poder predictivo estimado en el 72\% (Bonicatto, 1998). El puntaje de corte a ser utilizado — mayor o igual a 13 - fue utilizado en estudios epidemiológicos previos realizados en la ciudad de Buenos Aires (Lasa et al., 2000).

\section{Procedimiento}

Para realizar la recolección de datos fue llevado a cabo un muestreo teórico intencional (Hernández Sampieri, Fernández Collado \& Baptista Lucio, 2006). Se llevaron a cabo entrevistas en profundidad sobre las características presentes en la evocación de RsAs significativos sobre eventos específicos de vida. Las entrevistas fueron realizadas durante los años 2011- 2012 en la ciudad autónoma de Buenos Aires (Argentina).

Los individuos sin TDM fueron contactados por medio del procedimiento de bola de nieve (Hernández Sampieri, Fernández Collado \& Baptista Lucio, 2006) a partir del cual se fue ampliando la muestra de participantes hasta alcanzar el criterio de saturación de la información. Los individuos con TDM fueron reclutados de diferentes centros de salud de la ciudad autónoma de Buenos Aires (Hospital B. Rivadavia, B.A. Psychiatric Research Center y consultorios de la práctica privada). Los mismos recibieron un diagnóstico de TDM, de forma previa al estudio, por parte de médicos psiquiatras pertenecientes a las instituciones de salud (American Psychiatric Association, 2000). De forma complementaría, además, junto con la entrevista se les administró el IDB.

Ambos grupos de participantes, al momento de la admisión al estudio, firmaron el consentimiento informado para que los datos brindados fueran utilizados para la respectiva investigación (Anexo I). 
En dicho consentimiento, libre y voluntario, se garantizó el futuro anonimato de la información brindada. Las instituciones de salud aprobaron la presentación del protocolo de investigación en los respectivos comités de docencia e investigación y comité de ética con aprobación posterior, donde correspondiera, del comité central del gobierno de la ciudad de Buenos Aires. Los profesionales de los centros de salud, informados de las características del estudio, derivaron pacientes que se encontraran cursando un trastorno depresivo mayor y que se mostraran dispuestos a participar firmando el consentimiento informado. Para los individuos que se abstuvieron de participar en el estudio $\left(\mathrm{n}_{\mathrm{TDM}}=1\right)$, fue garantizada la ausencia de consecuencias en el tratamiento recibido.

Ambos grupos de participantes respondieron a la consigna oral "Por favor, elija un suceso de su vida personal que usted considere muy importante (ya sea un recuerdo agradable o desagradable, reciente o lejano) e intente recordar todos los detalles posibles sobre el mismo. $\mathrm{Su}$ recuerdo debe ser sobre un evento específico que le haya ocurrido, un hecho puntual, con una duración temporal menor a un día”. Posteriormente se realizaron preguntas de profundización en torno a las características fenomenológicas mencionadas en estudios previos sobre MA (Denkova, Dolcos \& Dolcos, 2012; Sutin \& Robins, 2007). Por ejemplo; ¿Recuerdas si sentiste alguna sensación táctil, visceral o de dolor en particular? ¿Recuerdas imágenes? ¿Qué detalles visuales podrías mencionar? ¿La imagen actual del recuerdo se te presenta como si la estuvieras viendo desde afuera (como lo vería un observador externo o un testigo) o se te presenta como si estuvieras viendo lo mismo que viste en ese momento?

Las entrevistas fueron registradas con un grabador de voz y luego transcriptas en formato digital para su análisis computarizado. Las mismas fueron realizadas en los consultorios individuales de las instituciones de salud. En el caso de la muestra control, los participantes fueron invitados a un consultorio privado de condiciones ambientales similares. La administración de las técnicas fue realizada de forma balanceada (la mitad de la muestra dentro de cada grupo respondió en primer lugar al IDB y luego se realizó la entrevista y viceversa). 
Procesos de rigor. En pos de buscar garantizar la validez de los datos recabados, a lo largo de todo proceso de investigación, fueron llevados a cabo distintos procedimientos de rigor. Se buscó mediante los mismos incluir e integrar distintas perspectivas sobre el objeto de estudio de acuerdo a la investigación social cualitativa (Denzin, 1978b, citado en Flick, 2004; Cornejo \& Salas, 2011). A través de un proceso de comparación permanente, se incorporaron distintas fuentes de información, tales como la inclusión de participantes de características etarias y educativas diversas así como pacientes provenientes de instituciones de salud privadas y públicas. Fueron implementados distintos métodos para abordar la comprensión del fenómeno y los resultados del estudio. Durante todo el proceso, se cotejaron e integraron los datos encontrados con documentaciones y trabajos previos en el tema. Además, bajo el método de comparación constante, los distintos nodos de información identificados fueron contrastados entre sí a lo largo de todo el estudio. De igual manera, se realizó una triangulación de investigadores (las autoras M.L.; S.A. y una psicóloga del equipo, M.S.C) para incrementar la validez de las categorías y los distintos análisis.

\section{Análisis de datos}

Para el análisis de los RsAs reportados se adscribió al enfoque de la Teoría Fundamentada en los Hechos (Strauss \& Corbin, 1998). Dicho enfoque es un método inductivo para el desarrollo de modelos teóricos donde la selección muestral, la recolección de datos y el análisis de los mismos son implementados simultáneamente en fases integradas e interrelacionadas. Se adscribió a dicho enfoque considerando las particularidades del material a ser analizado y en base a los objetivos del estudio (Strauss \& Corbin, 1998). A partir de los mismos, se buscó identificar y articular posibles modalidades experienciales de evocación subyacentes al discurso de los participantes respecto a experiencias de vida significativas.

Se utilizó el software Atlas.ti (Dowling, 2008) como soporte técnico para el análisis de los datos. Fueron efectuados los análisis de tipo descriptivo, axial y sistemático (Strauss \& Corbin, 1998). A partir de 
la transcripción de las entrevistas, fueron resaltados distintos pasajes, fragmentos, conceptos y formulaciones claves. A través del procedimiento de comparación constante de los datos, fue posible identificar un primer nivel de significados y categorías emergentes (codificación abierta). En cuanto al análisis de tipo axial, fueron rearticuladas las categorías y datos obtenidos en la codificación inicial. Los esquemas resultantes, fueron analizados selectivamente buscándose identificar los modos de presentación y vinculación de las categorías en base a distintos ejes conceptuales. Posteriormente, durante el análisis relacional, se procedió a la descripción de la categoría central encontrada.

\section{Resultados}

Los individuos con y sin TDM evocaron RsAs referidos a eventos significativos de vida. Ambos grupos de participantes describieron distintas características acerca de la experiencia recordada.

Considerando trabajos previos en el tema (D'Argembeau, Comblain \& Van der Linden, 2003; Thomsen, Schnieber \& Olesen, 2011) y el eje narrativo principal de cada recuerdo, los RsAs fueron agrupados en las siguientes categorías temáticas: nacimientos, fallecimientos, logros, eventos en los que estuvo en riesgo la integridad personal o de terceros, situación vincular, episodio de esparcimiento, inicio/finalización de un ciclo y un evento de la infancia temprana.

En relación a las características fenomenológicas referidas durante la evocación de los RsAs, fueron identificadas siete categorías emergentes del discurso (codificación abierta), dos modalidades básicas de vinculación de sus componentes (análisis axial) y una categoría teórica dicotómica central (análisis sistemático).

Si bien se identificaron distintos contenidos temáticos, las dimensiones fenomenológicas emergentes durante la evocación de RsAs fueron las mismas. Además, no se observaron diferencias en el tipo de dimensiones fenomenológicas referidas de acuerdo al grupo de procedencia de los participantes (análisis descriptivo). Por tanto, las categorías 
fenomenológicas identificadas fueron equivalentes tanto entre las distintas temáticas de los RsAs como entre el grupo con y sin TDM. Sin embargo, como se desarrollará en los apartados correspondientes (ver Análisis Axial y Análisis Sistemático), el grupo de individuos con TDM presentó un perfil diferencial en cuanto a la modalidad de evocación, utilizada para referir dichas categorías fenomenológicas, en comparación al grupo control.

La categoría central hallada (estilo de evocación multimodal vs. amodal) dio cuenta de cómo los RsAs manifestados pueden aproximarse a partir del entrecruzamiento de los ejes específico/generalizado y retórico/proposicional (análisis sistemático). A partir de la consideración de tal entrecruzamiento, resultó posible delimitar la emergencia de distintos estilos fenomenológicos de evocación, entre los individuos, de acuerdo a la presencia o ausencia de TDM.

\section{Análisis descriptivo}

A continuación se presentan las siete categorías fenomenológicas emergentes del discurso: (1) imaginería visual, (2) sensorialidad, (3) afectividad, (4) claridad, (5) perspectiva temporal, (6) subjetividad y (7) intersubjetividad. Las frecuencias de aparición de las categorías y sus respectivos códigos pueden observarse en la Tabla 2 .

\section{Imaginería visual}

Imágenes. Durante la evocación de los RsAs, ambos grupos de participantes refirieron reexperimentar imágenes y detalles visuales sobre lo sucedido. Este componente fue uno de los primeros en ser mencionados al describir el evento. Los detalles visuales fueron descritos de modo general, con solo unas pocas referencias o bien fueron delimitados aspectos determinados de la experiencia visual (rostros de otras personas presentes, colores y formas de los objetos, entre otros). Cuando los participantes evocaron imágenes de modo específico, las referencias fueron acompañadas con expresiones indicativas de un alto grado de vivacidad. 


\section{Tabla 2}

Dimensiones fenomenológicas emergentes del abordaje cualitativo

\begin{tabular}{|c|c|c|c|}
\hline Dimensión fenomenológica [n (\%)] & $\begin{array}{c}\text { Total } \\
\text { muestra }\end{array}$ & $\begin{array}{c}\text { Grupo con } \\
\text { TDM }\end{array}$ & $\begin{array}{c}\text { Grupo sin } \\
\text { TDM }\end{array}$ \\
\hline \multicolumn{4}{|l|}{ Imaginería visual } \\
\hline Imágenes & $33(97.1)$ & $15(93.8)$ & $18(100)$ \\
\hline Colores & $26(76.5)$ & $8(50.0)$ & $18(100)$ \\
\hline Perspectiva visual de primera persona & $26(76.5)$ & $12(75.0)$ & $14(77.8)$ \\
\hline Luminosidad & $25(73.5)$ & $10(62.5)$ & $15(83.3)$ \\
\hline Perspectiva visual de tercera persona & $15(44.1)$ & $5(31.3)$ & $10(55.6)$ \\
\hline Ambas perspectivas visuales & $9(26.5)$ & $2(12.5)$ & $7(38.9)$ \\
\hline Blanco y negro & $5(76.5)$ & $5(31.3)$ & $0(0)$ \\
\hline \multicolumn{4}{|l|}{ Sensorialidad } \\
\hline Sonidos & $21(61.8)$ & $9(56.3)$ & $12(66.7)$ \\
\hline Sensaciones táctiles & $20(58.8)$ & $7(43.8)$ & $13(72.2)$ \\
\hline Olores & $16(47.1)$ & $4(25.0)$ & $12(66.7)$ \\
\hline Sabores & $2(5.9)$ & $1(6.3)$ & $2(11.1)$ \\
\hline \multicolumn{4}{|l|}{ Afectividad } \\
\hline Reexperimentación & $24(70.6)$ & $11(68.8)$ & $13(72.2)$ \\
\hline Emociones positivas & $19(55.9)$ & $5(31.3)$ & $15(83.3)$ \\
\hline Emociones negativas & $15(44.1)$ & $14(87.5)$ & $4(22.2)$ \\
\hline Claridad & $31(91.2)$ & $14(87.5)$ & $17(94.4)$ \\
\hline Perspectiva temporal & $34(100)$ & $16(100)$ & $18(100)$ \\
\hline Momento del día & $32(94.1)$ & $16(100)$ & $16(88.9)$ \\
\hline \multicolumn{4}{|l|}{ Subjetividad } \\
\hline Importancia por lo que representa & $19(55.9)$ & $12(75.0)$ & $7(38.9)$ \\
\hline Importancia por los cambios & $19(55.9)$ & $11(68.8)$ & $8(44.4)$ \\
\hline Importancia por las emociones & $9(26.5)$ & $4(25.0)$ & $5(27.8)$ \\
\hline Importancia por ser la 1 era vez & $7(20.6)$ & $0(0)$ & $7(38.9)$ \\
\hline Importancia por el logro & $3(8.8)$ & $1(6.3)$ & $2(11.1)$ \\
\hline \multicolumn{4}{|l|}{ Intersubjetividad } \\
\hline Hablar con otros & $18(52.9)$ & $6(35.5)$ & $12(66.7)$ \\
\hline Diálogos & $22(64.7)$ & $10(62.5)$ & $12(66.7)$ \\
\hline Recordar caras & $11(32.4)$ & $6(37.5)$ & $5(27.8)$ \\
\hline
\end{tabular}


Los individuos refirieron una o varias imágenes asociadas al recuerdo. Los participantes que recordaron más de una imagen hicieron alusión a la experiencia de evocación como un fenómeno dinámico donde las imágenes se van sucediendo, unas a las otras, mientras se relata el evento. "Aparecen imágenes que van pasando como en una filmación" (S/TDM, mujer, 28 años, soltera, universitario completo, RA de 20 años de antigüedad, valencia negativa).

Las imágenes referidas con dinamismo también se presentaron acompañadas en su descripción de otras imágenes estáticas, experimentadas como un flash. "Las imágenes que te cuento aparecen primero mas tipo película, después solo imágenes tipo flashes. (S/TDM, mujer, 28 años, soltera, universitario completo, RA de 20 años de antigüedad, valencia negativa).

Los participantes describieron, así, una secuencia de eventos y de imágenes: "Recuerdo primero la serie de instrucciones que nos dieron los adultos y después el potrillo que se levanta y no sé qué exactamente qué pero seguro una tía que no tenía nada que ver con eso. Nada que ver. Se me pasa la imagen a otra cosa pero que era dentro de ese campo, pero imagino que fue un juego, algo afuera, se interrumpió eso y quedo ahí como que no seguimos en el lugar" (S/TDM, mujer, 46 años, divorciada, secundario incompleto, RA de 37 años de antigüedad, valencia positiva).

Los participantes utilizaron distintos recursos retóricos para describir la experiencia visual de evocación, por ejemplo, analogías con la experiencia visual del flash y de la fotografía, para hacer alusión a las imágenes estáticas o, en caso de ser dinámicas, se utilizó la metáfora de la filmación.

Además, en el caso de contar con varias imágenes, los participantes destacaron una imagen principal, evocada esta con varios detalles, mientras que las otras imágenes fueron referidas de modo más generalizado.

No todos los individuos con TDM pudieron evocar imágenes (ver Tabla 2). En estos casos la valencia emocional del RA resultó ser negativa. Especialmente, las personas con TDM hicieron uso de descripciones breves y de rasgos generalizados. "Cuando estaba con él en el control y después cuando empezó con vómitos y convulsiones, pero en si 
imágenes no estoy segura”(C/TDM, mujer, 60 años, divorciada, secundario incompleto, RA de 21 años de antigüedad, valencia negativa).

En el grupo de participantes con TDM, las referencias visuales asumieron rasgos vagos no observándose, de modo característico, la delimitación de detalles puntuales ni el uso de recursos retóricos para su descripción. Solo en los casos en los que los participantes con TDM precisaron detalles visuales de modo específico, estos utilizaron términos relativos a la presencia de movimiento o dinamismo.

Cuando ambos grupos de participantes accedieron a detalles específicos, de tipo visual, estos estuvieron acompañados en su descripción por referencias afectivas. Las referencias espaciales fueron especificadas para los distintos recuerdos por todos los participantes. El lugar del hecho fue señalado en términos nominales (como ser el nombre de la clínica o de la ciudad), mediante detalles visuales (generales y/o específicos) y, en algunos recuerdos, el lugar también fue descrito mediante otros componentes sensoperceptivos (véase más adelante, el componente olfativo y el componente afectivo).

Colores. Los participantes con y sin TDM que durante la evocación del RsAs accedieron a detalles visuales específicos destacaron, como parte de la descripción del recuerdo, la presencia de colores. Fueron realizadas descripciones de las imágenes en donde un color primaba por sobre el resto.

A su vez, otros participantes refirieron imágenes que se presentaron únicamente en tonos de grises o de blanco y negro. Esto último se observó en los recuerdos de valencia negativa. Por otro lado, cuando las imágenes fueron evocadas de un modo breve y generalizado no se explicitó ningún color. Característicamente, por medio de verbos de movimiento (tales como alcanzar, llegar, ir, entre otros), se expresó no poder recordar ese tipo de detalles.

Las personas con TDM que evocaron colores presentes en las imágenes, hicieron particular referencia a tonos de grises, blancos y negros. En todos estos casos los recuerdos fueron de valencia emocional negativa.

Luminosidad. Durante la descripción de las imágenes evocadas, ambos grupos de participantes hicieron alusión a detalles lumínicos. 
Al dar cuenta del tipo de luz presente en las imágenes, los individuos especificaron referencias sensoriales y temporales sobre el momento del día, clima e inclusive el momento del año. "Diría que era la mañana o el mediodía por la cantidad de luz que había, la tarde temprano" ( $\mathrm{S} /$ TDM, hombre, 43 años, soltero, universitario completo, RA de 4 años de antigüedad, valencia positiva).

Además, las descripciones relativas a la luminosidad fueron referidas mediante expresiones indicativas de un alto grado de vivacidad. También, fueron referidas sensaciones corporales e interoceptivas. A su vez, la descripción fue especificada en relación a otras aristas fenomenológicas como ser las referencias afectivas. No se observaron diferencias en el discurso en cuanto a la especificación de la luminosidad entre ambos grupos de participantes.

Perspectiva visual. Los participantes con y sin TDM, al describir los distintos detalles presentes en las imágenes, refirieron una perspectiva visual de primera persona, de tercera persona, ambas o ninguna. La perspectiva visual de primera persona fue referida en recuerdos de valencia emocional positiva y negativa. En estos casos, los participantes indicaron un volver a reexperimentar el evento. También se utilizaron expresiones sobre como el evocar el recuerdo implicó un re-introducirse visualmente en el mismo. En estos casos se indicó como la perspectiva visual de primera persona fue experimentada como un reingreso que, inclusive, posibilitaría el volver a sentir al menos parte de lo vivido durante el evento. La perspectiva de primera persona fue referida en recuerdos donde la experiencia de evocación estuvo acompañada por expresiones de vivacidad.

Los detalles presentes en las imágenes de los recuerdos evocados desde una perspectiva visual de tercera persona, fueron referidos de modo breve. Los participantes expresaron cierta distancia o diferenciación respecto al sí mismo del recuerdo. "Como de afuera, yo miro a la nena que era" (S/TDM, mujer, 46 años, divorciada, secundario incompleto, RA de 37 años de antigüedad, valencia positiva). A su vez, las imágenes evocadas desde una perspectiva de tercera persona, también hicieron alusión a verbos de movimiento. 
Por otro lado, algunos participantes refirieron poder evocar a la imagen de forma alternada, es decir, desde una perspectiva de tercera y primera persona. En los casos en los que se refirió más de una imagen asociada al recuerdo, los participantes refirieron perspectivas visuales diferentes de acuerdo a las imágenes evocadas. En los casos donde las imágenes fueron referidas de un modo generalizado, las personas indicaron no poder especificar la perspectiva visual. Se refirió la ausencia de un sujeto, protagonista o testigo visual y la referencia a otros detalles visuales también fue escasa.

\section{Sensorialidad}

Sonidos. Los participantes con y sin TDM especificaron distintos sonidos presentes durante el evento recordado tales como voces, diálogos, sonidos de la naturaleza, música, sirenas y maquinas (ver Tabla 2). A diferencia de lo reportado durante la evocación de imágenes, no se observaron expresiones relativas a un volver a "escuchar" los sonidos de la experiencia original.

No obstante, si bien los sonidos no fueron descritos a un nivel reexperiencial, la evocación de los mismos fue especificada mediante alusiones a otras vivencias sensoriales del evento. "Lo que más recuerdo es que el lugar era muy grande, muy amplio y muy frío. Creo que era invierno, entonces los sonidos que había se escuchaban en ese vacío. Eran los sonidos vinculados con lo que pasaba ahî" (S/TDM, mujer, 46 años, divorciada, secundario incompleto, RA de 37 años de antigüedad, valencia positiva). Asimismo, no se observaron diferencias entre los individuos con y $\sin$ TDM en las expresiones utilizadas durante la evocación de los sonidos relativos al evento recordado.

Sensaciones táctiles. Fueron evocadas distintas sensaciones táctiles experimentadas durante el evento. Fueron referidas sensaciones exteroceptivas e interoceptivas. Al igual que con las imágenes, se refirió el volver a experimentar al presente sensaciones similares a las ocurridas durante el evento.

En el caso de individuos con TDM, las sensaciones referidas se encontraron vinculadas a recuerdos desagradables. "La sensación es, te 
viene, recordás a tu mamá y te viene, como que algo en el cuerpo te da un calambrecito, algo de eso" (C/TDM, hombre, 47 años, soltero, secundaria incompleta, RA de 5 años de antigüedad, valencia negativa).

La experiencia táctil fue referida como una sensación que le viene o que le agarra al individuo al evocar el RA. No se observaron diferencias entre los individuos con y sin TDM en el modo de referir las sensaciones táctiles. Ambos grupos evocaron distintas sensaciones a su vez que refirieron vivencias de reexperimentación al evocar dichas sensaciones corporales.

Olores. Los grupos de participantes refirieron recordar distintos olores presentes durante el evento. Los dos grupos describieron los olores en relación al lugar donde ocurrió el evento y al tono afectivo de la vivencia. No se observaron diferencias, entre ambos grupos, en el modo de referir y de evocar aquellos aspectos relativos al olfato.

Ambos grupos de participantes indicaron olores vinculados al lugar (olor a hospital, al hogar, entre otros), olores de perfumes, de desperdicios y de comidas (ver Tabla 2). Si bien los participantes pudieron precisar distintos olores, a diferencia de la evocación de los detalles visuales o táctiles, estos no fueron referidos como siendo reexperimentados al presente.

Sabores. La referencia a estímulos gustativos fue realizada solo cuando el evento evocado implicó situaciones donde se ingirió alimentos, o bien, donde los niveles afectivos resultaron intensos. A diferencia del sentido de la visión o de la audición, donde la experiencia de estos sentidos pudo ser mayoritariamente especificada, pero al igual que en caso del olfato, solo en algunos recuerdos se percibieron sabores distintivos mientras tuvo lugar el evento. No se observaron diferencias entre ambos grupos de participantes en el modo de referirse a la evocación de los sabores.

\section{Afectividad}

Al solicitarles a los participantes un recuerdo significativo, las emociones experimentadas durante el evento fueron evocadas de modo específico por los participantes. Los individuos sin TDM indicaron haber sentido durante el evento tanto emociones positivas (83.3\%) 
como negativas (22.2\%). Es decir, experimentar una emoción agradable no excluyó la posibilidad de sentir simultáneamente emociones desagradables.

Al describir las emociones, los participantes detallaron distintas sensaciones corporales. Los participantes con y sin TDM expresaron además que, con el paso del tiempo, las emociones se vieron atenuadas o inclusive modificadas por la aparición de emociones nuevas. Los individuos manifestaron experimentar, al momento de la evocación, emociones varias. Estas fueron referidas como emociones similares o bien como emociones diferentes a las experimentadas durante el evento.

Los individuos con TDM también evocaron recuerdos donde refirieron haber sentido emociones de valencia negativa $(87.5 \%)$ como positiva (31.3\%). Los participantes con TDM refirieron a las emociones displacenteras del recuerdo como algo que les queda, permaneciendo junto con la narrativa del recuerdo, y que, al evocarlo, es algo que les viene. Los participantes con TDM indicaron volver a experimentar, al presente, las emociones sentidas durante el evento.

En cuanto a los recuerdos de valencia positiva, si bien los participantes con TDM especificaron las emociones sentidas durante el evento, estas no siempre fueron referidas como siendo reexperimentadas al presente.

\section{Claridad}

Los participantes, con y sin TDM, indicaron evocar de un modo vívido distintos detalles y momentos del evento recordado. Los participantes refirieron un alto grado de vivacidad al describir los componentes visuales y/o emocionales.

Los participantes dieron cuenta de experiencias vívidas de evocación por medio del uso de recursos retóricos. De esta manera, se buscó expresar la presencia de movimiento en las imágenes o bien cierto movimiento del sí mismo en el tiempo. "Y me vienen imágenes pero como que...como que viajo de vuelta a Bariloche, como que viajo a estar de nuevo con esas personas, como que voy a esa edad y ...como que me vienen un montón de imágenes" (S/TDM, mujer, 28 años, 
soltera, universitario completo, RA de 10 años de antigüedad, valencia negativa).

El recordar con vivacidad fue mencionado en relación a poder describir un transcurso de tiempo, un continuo temporal. "Recuerdo bien ese fin de semana, te lo puedo describir hora por hora" (C/TDM, mujer, 58 años, en pareja, universitario incompleto, RA de 1 año de antigüedad, valencia negativa).

Las referencias respecto a la vivacidad fueron expresadas junto con indicaciones relativas a la importancia subjetiva del recuerdo. "Sé que eso estaba, que eso paso, sí. Para mí ese fue un momento muy fundamental" (S/TDM, mujer, 28 años, soltera, universitario completo, RA de 4 ańos de antigüedad, valencia positiva).

Al expresar la vivacidad de la evocación, fueron referidas experiencias de reexperimentación. Por otro lado, los participantes también refirieron sensaciones de modo vívido, indicando certeza respecto a su veracidad, pero sin volver a experimentarlas nuevamente al presente. De esta manera, el recordar de un modo vívido no necesariamente implicó para los participantes volver a experimentar dichos aspectos.

Las expresiones de vivacidad emergieron principalmente cuando los participantes evocaron de modo específico detalles del recuerdo. En aquellos casos donde la evocación presentó características poco claras, generalizadas o confusas, los participantes hicieron referencia a la antigüedad y/o intensidad emocional del recuerdo como factores que estarían dificultando un acceso vívido.

Los individuos con TDM hicieron referencia a la vivacidad de la evocación particularmente para los aspectos emocionales del recuerdo. En menor medida, este grupo de participantes utilizó expresiones indicativas de vivacidad para los detalles visuales y sensoriales. "En cuanto a la emoción es como si lo estuviera viviendo casi. En cuanto a la percepción del detalle, es borroso." (C/TDM, mujer, 54 años, divorciada, universitario completo, RA de 4 años de antigüedad, valencia positiva). 


\section{Perspectiva temporal}

Los participantes con y sin TDM indicaron coordenadas temporales para el evento evocado. Se observaron grados diversos de especificación (como ser la fecha numérica para día, mes, año y edad personal). A su vez, la ubicación temporal fue puntualizada no solo mediante referencias convencionales sino también mediante detalles relacionados al tipo de clima, la estación del año, el momento del día, la temperatura del ambiente o el grado de luminosidad presente en los componentes fenomenológicos evocados.

La localización temporal a partir de la fecha numérica fue establecida particularmente para eventos sociales, nacimientos y muertes. La fecha del suceso fue especificada por los participantes de modo automático o bien la misma fue referida como resultado de procesos de estimación. En este sentido, se observó la mención a otras referencias personales como recurso a partir del cual el participante pudo inferir el día, el mes o el año. En cambio, el momento del día en el que tuvo lugar el evento pudo ser especificado de forma directa. "La fecha precisa no, sé que era diciembre. Podría llegar a recordar el año, pero tendría que ponerme a pensar. No es que me sale inmediatamente. Recuerdo sí que fue de noche" (C/TDM, mujer, 53 ańos, divorciada, universitario completo, RA de 4 años de antigüedad, valencia positiva).

No se observaron diferencias entre el grupo de participantes con y sin TDM en relación al modo de referir la ubicación temporal del evento.

\section{Subjetividad}

Los recuerdos evocados por el grupo de individuos con y sin TDM fueron referidos como eventos que simbolizan el modo en el que ellos se conciben a sí mismos, a otros significativos o bien se relacionan con un momento de particular importancia biográfica. En este último caso se hizo referencia, por ejemplo, al inicio o cierre de una etapa, un antes $\mathrm{y}$ un después.

El evento recordado y su impacto en el sí mismo fueron además referidos en relación a como a partir del evento ocurrieron cambios 
en el modo de interpretar distintos sucesos, asumiéndose en adelante otro tipo de comportamiento frente a situaciones similares. Además algunos participantes, con y sin TDM, hicieron referencias a las reflexiones o pensamientos ocurridos durante el evento. Particularmente en el grupo de individuos con TDM algunos de los pensamientos fueron expresados a modo de interrogantes. Cuando los participante refirieron no recordar los pensamientos, estos utilizaron expresiones relativas a un no llegar a recordar ese aspecto de la vivencia.

Los participantes también vincularon al evento y a los momentos de su evocación con el modo en el que ellos se conciben a sí mismos. Fueron mencionadas distintas conductas y pensamientos sucedidos durante el evento con los que en la actualidad el participante aún se siente identificado o por el contrario, características personales con las que en la actualidad se diferencia.

\section{Intersubjetividad}

Durante la evocación de los RsAs fue mencionada, de forma reiterada por el grupo de participantes con y sin TDM, la presencia de otras personas. Además, fueron realizadas referencias en relación a cómo los otros se tornaron en referentes en relación al hecho recordado o bien, cómo se piensa a los otros a través de dicho evento.

Solo algunos participantes refirieron evocar de forma puntual los rostros de otras personas. No obstante los participantes, que presentaron dificultades para recordar los rostros de forma puntual, sí pudieron precisar a nivel general o nominal quienes formaron parte de lo recordado.

Durante la descripción de los RsAs se hizo referencia a otras personas bajo un formato de carácter amodal (mencionando el nombre) o bien mediante la alusión a componentes fenomenológicos (describiendo principalmente detalles faciales o la contextura física). En el primer caso, podría entendérselo como información de carácter proposicional antes que experiencial en tanto no se presentan referencias fenomenológicas. Solo se sabe que había otras personas pero no se cuenta con información vivencial que lo respalde. 
Los participantes refirieron haber hablado a posteriori con otras personas, presentes o no durante el evento, respecto a lo sucedido. Especialmente se indicó relatar el evento en circunstancias sociales donde se conversa sobre alguna temática en particular para la cual el RA es utilizado a modo de ejemplo ilustrativo. Otros individuos, en cambio, refirieron no haber contado a los demás el recuerdo si bien aclararon no tener reparo en hacerlo.

\section{Análisis axial}

Durante la evocación de RsAs fueron referidos distintos componentes fenomenológicos. Cuando se delimitaron de modo específico detalles del evento, su descripción implicó expresiones indicativas de un alto grado de vivacidad. En cambio, cuando los participantes los refirieron de un modo global no se hizo alusión a la experiencia de evocación. En estos casos la descripción del recuerdo fue más bien breve y orientada a información fáctica antes que vivencial.

Ambos grupos señalaron a las imágenes como formando parte del mismo proceso de recordar. Las mismas fueron descriptas utilizándose como eje al grado de luminosidad, a la perspectiva visual de recuperación y a la presencia de colores. A su vez, durante su descripción fueron utilizadas otras referencias sensoperceptivas y emocionales. Si bien los participantes hicieron referencia al tipo de luminosidad visual, solo algunos especificaron en detalle los rostros de las otras personas o características de ciertos objetos. La especificación lumínica se presentó como de acceso directo, sin expresarse aparente esfuerzo para su evocación. Tal disposición contrasta con dificultades manifestadas por los individuos con TDM para acceder de modo específico a otros detalles fenomenológicos. "Más bien, recuerdo de modo muy global y con el esfuerzo voy tratando de precisar cosas" (C/TDM, mujer, 54 años divorciada, universitario completo, RA de 4 años de antigüedad, valencia positiva).

Se observó la utilización de recursos retóricos particularmente durante la descripción de detalles específicos. Fueron empleadas metáforas sobre el movimiento implicado en la experiencia de evocación de los componentes visuales y emocionales. Se utilizaron analogías sobre la 
experiencia visual relativa a filmaciones o fotografías. Cuando el recuerdo fue evocado de modo específico, por ejemplo describiéndose objetos y rostros, la evocación fue acompañada por medio de verbos dinámicos. En cambio, cuando los recuerdos fueron referidos de un modo generalizado, se observó la utilización de expresiones sobre la ausencia de movimiento. Fueron utilizadas expresiones en relación a un "no salir de" o "no llegar a".

Para los individuos sin TDM, la perspectiva visual de primera persona fue la modalidad predominante de evocación. La perspectiva visual de tercera persona fue referida por los participantes con TDM mediante expresiones de distanciamiento respecto al sí mismo del recuerdo (e.g. "veo a la nena que era"). En relación a la temporalidad, ambos grupos de participantes especificaron coordenadas temporales exactas o aproximadas. Se observó el uso de información fenomenológica para orientarse en el tiempo (tal como el tipo de luz, la temperatura). También se hizo uso de referencias personales (como ser el señalamiento de la edad), se delimitó un período de vida en particular o bien, se utilizaron descriptores experienciales.

A su vez, el suceso fue referido por los participantes como un RA de importancia subjetiva en tanto representante de un determinado período de la vida o bien de algún aspecto característico del sí mismo. Ambos grupos de participantes emplearon expresiones relativas a la importancia de dicho recuerdo. Además, los participantes refirieron que las emociones implicadas le brindan importancia subjetiva a dicho recuerdo. Otros participantes refirieron la importancia del evento en cuanto a las implicancias derivadas del mismo, la delimitación de un antes y un después en el curso vital. En este sentido, ya sea por expresiones de identificación o por medio de expresiones de distanciamiento, se hizo alusión a como se concibe al sí mismo en el presente a través del recuerdo.

Durante la evocación de los RsAs, se indicó de forma reiterada la presencia de otras personas durante el evento. Además, fueron referidas conversaciones posteriores con quienes estuvieron presentes. Inclusive, el volver a interactuar con los otros (de forma posterior al suceso), fue referido como un estímulo para la evocación, un recordatorio. Del mismo modo, los RsAs fueron referidos como aspectos del sí mismo o eventos representativos de la relación con los otros. 


\section{Análisis sistemático}

El evocar los componentes fenomenológicos del evento emergió como un proceso asociativo a partir del cual se fue recordando la experiencia de vida. En el presente trabajo y por fines analíticos, los distintos componentes fenomenológicos fueron descritos de modo diferencial encontrándose, no obstante, relacionados. Dichos componentes pueden ser así comprendidos como distintos atributos experienciales emergentes de un mismo fenómeno de evocación. Por otro lado, si bien cada vivencia es única, los RsAs analizados presentaron características estructurales afines a ambos grupos de participantes. Resulta entonces posible identificar estilos fenomenológicos de evocación distintivos de acuerdo al entrecruzamiento de los siguientes dos ejes primarios:

Continúo especificidad-generalidad (nivel de evocación). Por un lado, los componentes fenomenológicos fueron referidos de un modo específico detallándose distintas características de los RsAs de un modo puntual. En estos casos, los detalles del evento fueron recordados de forma precisa. Fueron utilizadas expresiones relativas a un revivir la experiencia. El evento se recuerda "patente", "con lujo de detalles". Por otro lado, particularmente en el grupo de individuos con TDM, se describió al recuerdo de un modo generalizado, siendo los detalles poco precisos y su descripción breve. En estos casos, si bien se relató la trama narrativa del evento, no resultaron características las descripciones fenomenológicas, las expresiones de vivacidad ni de re-experimentación.

Continúo retórico-proposicional (formato representacional). Cuando los RsAs fueron referidos en detalle y con expresiones de vivacidad, en pos de describir los componentes fenomenológicos de los recuerdos, los participantes hicieron uso de expresiones retóricas. En este caso, se emplearon recursos metafóricos y analógicos que buscaron comunicar aspectos experienciales de la vivencia. En sentido contrario, la modalidad de evocación de los componentes fenomenológicos de los RsAs también asumió un uso predominante de proposiciones. Dicho tipo de evocación no presentó, de modo distintivo, el uso de expresiones relativas a la vivacidad del recuerdo. La información relativa al evento 
de vida fue descripta de un modo fáctico y conciso. En estos casos los participantes describieron aspectos fenomenológicos del recuerdo, bien por medio de rasgos generales o bien por medio de detalles específicos.

Entrecruzamiento. A partir del análisis del discurso de ambos grupos y del entrecruzamiento de ambos contínuums de evocación (especifico-generalizado/retórico-proposicional), pueden plantearse modalidades distintivas de evocación entre los grupos de participantes (retóricas/proposicionales). El modo de referirse a los componentes fenomenológicos durante la evocación del evento asumió modalidades cualitativamente diferentes entre el grupo con y sin TDM.

Los participantes con TDM tendieron a referir los recuerdos de modo generalizado sin hacer uso de recursos metafóricos de modo característico. Refirieron descripciones breves, pudiendo solo desarrollar en mayor detalle la vivencia fenomenológica de los componentes de carácter visual y emocional. Los participantes sin TDM, en cambio, refirieron experiencias de reexperimentación y utilizaron característicamente descripciones retóricas pudiendo describir de modo específico distintos componentes fenomenológicos.

Por lo tanto, puede plantearse que los individuos con TDM asumieron un estilo de evocación de tipo general-proposicional. El grupo de individuos sin TDM presentó, al contrario, un estilo de evocación específico-retórico, particularmente en lo que refiere a los componentes visuales, sensoperceptuales, emocionales y a los componentes vinculados a la experiencia de claridad.

\section{Categoría central}

Del análisis abierto, axial y sistemático de los RsAs emergió como categoría fenomenológica central una evocación de carácter bifásico. De acuerdo a la evocación de detalles específicos o generales, y al empleo de recursos retóricos o proposicionales, fue posible delimitar un estilo de evocación de los RsAs significativos de carácter multimodal o bien un estilo de evocación de carácter amodal (ver Figura 1). 


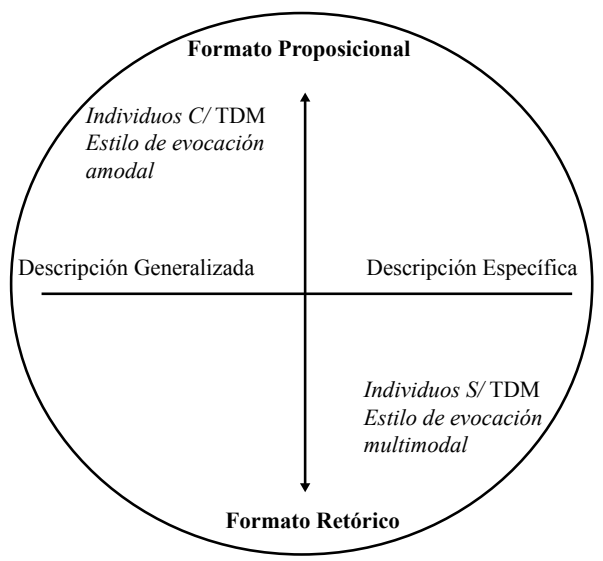

Figura 1. Estilos fenomenológicos de evocación

El estilo de evocación amodal, por tanto, se caracteriza por combinar las propiedades de la intersección entre una evocación predominantemente generalizada y proposicional. Al contrario, el estilo de evocación amodal, por tanto, condensa las propiedades provenientes de una evocación predominantemente específica y retórica.

\section{Discusión}

Sensorialidad, afectividad, memoria e identidad son funciones altamente relacionadas y, particularmente en interacción, cuando las personas evocan RsAs significativos (Bluck et al., 2005; Conway, 2005; Sutin \& Robins, 2007). En concordancia con trabajos previos (Montebarocci et al., 2014; Williams et al., 2007), los estilos fenomenológicos de evocación de los RsAs asumieron propiedades distintivas de acuerdo a la presencia o ausencia de un TDM. La manera en la que las personas recuerdan su pasado y por ende, aspectos de su identidad, se encuentra relacionado con modalidades particulares del procesamiento cognitivo de la información (Watkins \& Teasdale, 2004; Werner-Seidler \& Moulds, 2011b). En este trabajo se identificaron los estilos amodal y modal de evocación de RsAs. 
El presente trabajo tuvo como objetivo principal explorar los componentes y modalidades fenomenológicas de evocación de RsAs significativos de acuerdo a la presencia o ausencia de TDM. Los elementos fenomenológicos referidos fueron los mismos en el grupo con y sin TDM. Las categorías emergentes reunieron a los componentes: visuales, sensoperceptivos, emocionales, de claridad, de perspectiva temporal, de impacto en el sí mismo y de intersubjetividad. No obstante, fue posible identificar estilos distintivos de evocación entre los grupos de participantes. Estos hallazgos también se encuentran en sintonía con trabajos en los que se reportó componentes fenomenológicos compartidos entre distintos individuos pero se mostró, a su vez, diferencias en los modos de evocación de acuerdo a las características particulares del grupo de pertenencia (Montebarocci et al., 2014; Williams et al., 2007). Por tanto, puede proponerse que no sería el tipo de componentes fenomenológicos lo que distingue a los individuos con y sin TDM sino el modo en el que estos componentes son evocados. Podría pensarse en una estructura fenomenológica básica desde donde se evocan los RsAs y a partir de la cual, de acuerdo a la presencia o no de TDM, se consolidan estilos característicos de evocación. Las diferencias entre los grupos emergerían, así, de la modalidad particular de activación de dicha estructura (Conway, 2001; Watkins et al., 2008; Werner-Seidler \& Moulds, 2011b).

Del análisis de las entrevistas en profundidad, se encontró que el grupo de individuos con TDM evocó en mayor medida a sus RsAs bajo un estilo amodal. Esto es, los recuerdos fueron descritos de un modo global, observándose el acceso a detalles específicos particularmente al dar cuenta de la afectividad y, en menor medida, al describir los componentes visuales del evento. Los eventos fueron descriptos por medio de proposiciones factuales sin hacer uso de recursos retóricos para transmitir aspectos fenomenológicos del recuerdo. En cambio, los individuos sin TDM evocaron sus recuerdos bajo un estilo multimodal, refiriendo con mayor frecuencia una variedad amplia de componentes fenomenológicos y haciendo alusión a las vivencias experimentadas mediante expresiones retóricas. En consonancia con teorías en psicología clínica y de la memoria dentro del paradigma cognitivo (Watkins \& Teasdale, 
2004; Werner-Seidler \& Moulds, 2011b), los resultados obtenidos son compatibles con una visión de los RsAs como representaciones mentales complejas donde se aúnan aspectos proposicionales y analógicos de información (Barsalou, 2008; Watkins et al., 2008). Los RsAs no solo cuentan con información factual sino también con información experiencial proveniente de los distintos canales sensoriales y afectivos.

Por otro lado, las modalidades de evocación también se ubicaron en un continuo desde lo generalizado hacia lo específico. Ambos ejes pueden pensarse a la luz de las teorías que describen procesamientos de la información distintivos en los individuos con y sin TDM (Werner-Seidler \& Moulds, 2011b). En este sentido Watkins y Teasdale (2004) y Watkins (2008) han desarrollado en extenso descripciones acerca de un procesamiento abstracto de la información, de carácter rumiativo, generalizado y muchas veces desadaptativo, típico de las personas que padecen TDM. De acuerdo a distintos referentes en el tema (Werner-Seidler \& Moulds, 2011b; Williams, Teasdale, Segal \& Soulsby, 2000), la presencia de dificultades para entrar en contacto con la experiencia se encuentra asociada con dificultades para implementar estrategias de autorregulación emocional eficientes. De hecho, se sostiene que es esta misma tendencia de procesamiento abstracto la que se encontraría implicada en que los individuos con TDM presenten dificultades para realizar ejercicios de mindfulness y beneficiarse anímicamente de la evocación de RsAs positivos (Werner-Seidler \& Moulds, 2011b). El poder entrar en contacto con vivencias personales, el poder evocar los detalles fenomenológicos de un momento pasado, requiere de un procesamiento multimodal de la información (Barsalou, 2008). Es justamente el entrenamiento en dicha modalidad cognitiva de procesamiento específico de la información la que es promovida por los modelos terapéuticos de mindfulness para los desórdenes del espectro depresivo (Williams et al., 2000).

Consecuentemente, puede pensarse que promover un estilo de evocación específico (multimodal) de los RsAs significativos en individuos con TDM puede favorecerles. Los mismos serían así capaces de implementar, a posteriori, estrategias efectivas de autorregulación emocional. Poder acceder de modo específico a RsAs negativos para 
una mejor tramitación psicológica del hecho o, a recuerdos positivos, para beneficiarse anímicamente de su evocación, puede resultar de particular relevancia clínica para individuos que presentan o presentaron TDM (Werner-Seidler \& Moulds, 2011b).

En cuanto a las limitaciones del presente estudio, en primer lugar cabe remarcar el abordaje exploratorio y el alcance descriptivo de los resultados obtenidos. No obstante, dada la ausencia de investigaciones previas en la región y la falta de antecedentes respecto a los estilos fenomenológicos de evocación de RsAs significativos se consideró necesario examinar la fenomenología de los RsAs bajo la metodología implementada. Por razones operativas, además, el diseño muestral fue no probabilístico. Esta característica limita el alcance de las conclusiones a los grupos de individuos que aceptaron participar del trabajo. Sin embargo, no limita la confiabilidad y validez de los resultados encontrados en este grupo de participantes. Por otro lado, el mismo objeto bajo estudio suele ser fuente de diversas críticas en cuanto a la exactitud con la que opera la MA a nivel individual como colectivo (i,e., Klein et al., 2010 ). Sin embargo, en concordancia con líneas actuales de investigación (Montebarocci et al., 2014), no fue un objetivo evaluar la veracidad del contenido de los RsAs sino los perfiles fenomenológicos conformados durante los procesos de evocación de eventos de vida significativos. Y de hecho, antes que la veracidad del contenido, son las modalidades de procesamiento de la experiencia del recuerdo las que se encuentran asociadas con los sesgos cognitivos de los individuos con TDM y, en definitiva, con el impacto anímico asociado (Watkins \& Teasdale, 2004). No obstante, pese a las limitaciones del presente trabajo, se considera que los resultados alcanzados podrán ser de utilidad en próximas investigaciones en la temática. Si bien preliminares, se espera que los hallazgos encontrados puedan ser utilizados, además, en el perfeccionamiento y diseño de técnicas de evaluación e intervención clínica en lo que refiere al abordaje de los individuos con TDM.

En este estudio, por medio de la evocación de RsAs los individuos pudieron recrear, para sí mismos y para los otros, distintas experiencias de vida (Montebarocci et al., 2014). Conocer en cuales dimensiones fenomenológicas las personas con TDM presentan mayores déficits y 
la posibilidad de que dichas deficiencias puedan variar de acuerdo a determinadas características de los RsAs, resulta teórica y clínicamente relevante. Dicho conocimiento puede brindar una mejor comprensión del funcionamiento de la MA durante la presencia de TDM y, consecuentemente, favorecer el diseño de un abordaje terapéutico idóneo para cada paciente. Las intervenciones psicológicas para la depresión se podrían ver beneficiadas de atender explícitamente a las modalidades de procesamiento de la información experiencial, como ser las dimensiones fenomenológicas de los RsAs de los consultantes (Werner-Seidler \& Moulds, 2011a; Werner-Seidler \& Moulds 2011b).

Se espera que la continuación de las líneas de investigación que prosigan el abordaje fenomenológico de los RsAs posibilite ahondar en la comprensión relativa a como las personas, y en particular los individuos con TDM, se experimentan a sí mismos, a los otros y, a los distintos episodios que conforman su curso vital.

\section{Referencias}

American Psychiatric Association (2000). Diagnostic and statistical manual of mental disorders (4a. ed., texto rev.). Washington, DC: American Psychiatric Association.

American Psychiatric Association (2013). Diagnostic and statistical manual of mental disorders (5ta. ed.). Washington, DC: American Psychiatric Association. https://doi.org/10.1176/ appi.books.9780890425596

Anjuán, P., Pérez-García, A, Rueda, B. \& Ángeles-Ruiz, M. (2008). Estilos explicativos y afecto negativo. Revista de Psicopatología y Psicología Clinica, 13(1), 45-52. Recuperado de: http://revistas. uned.es/index.php/RPPC/article/view/4049/3903

Barsalou, L. W. (2008). Grounded cognition. AnnualReviewofPsychology, 59, 617-45. doi:10.1146/annurev.psych.59.103006.093639

Beck, A.T., Steer, R.A., Ball, R. \& Ranieri, W. (1996). Comparison of Beck Depression Inventories-IA and -II in psychiatric outpatients. Journal of Personality Assessment, 67, 588-597. https://doi.org/10.1207/s15327752jpa6703_13 
Bluck, S., Alea, N. \& Habermas, T. (2005). A tale of three functions: The self- report uses of autobiographical memory. Social Cognition, 23(1), 91-117. https://doi.org/10.1521/soco.23.1.91.59198

Bonicatto, S., Dew, M.A. \& Soria, J. (1998). Analysis of the psychometric properties of the Spanish version of the Beck Depression Inventory in Argentina. Psychiatric Research, 79:27785. https://doi.org/10.1016/S0165-1781(98)00047-X

Cláudio, V., Noronha, M. \& Balola, M. (2014). Olvido dirigido en la depresión mayor. Revista de Psicopatología y Psicología Clínica, 19(2), 105-115. http://dx.doi.org/10.5944/rppc.vol.19.num.2. 2014.13061

Conway, M. A. (2005). Memory and the self. Journal of Memory and Language, 53(4), 594-628. doi:10.1016/j.jml.2005.08.005

Cornejo, M. \& Salas, N. (2011). Rigor y calidad metodológicos: un reto a la investigación social cualitativa. Psicoperspectivas, 10(2), 12-34. doi: 10.5027/psicoperspectivas-vol10-issue2-fulltext-144.

Crawley, R. (2014). Trait mindfulness and autobiographical memory specificity. Cognitive Processing, 79-86. http://doi.org/10.1007/ s10339-014-0631-3

D’Argembeau, A., Comblain, C. \& Van der Linden, M. (2003). Phenomenal characteristics of autobiographical memories for positive, negative, and neutral events. Applied Cognitive Psychology, 17(3), 281-294. doi:10.1002/acp.856

Denkova, E., Dolcos, S. \& Dolcos, F. (2012). Reliving emotional personal memories: Affective biases linked to personality and sexrelated differences. Emotion, 12, 515-528. doi:10.1037/a0026809 Dowling, M. (2008). Atlas.ti (software). En L. Given (ed.), The SAGE encyclopedia of qualitative research methods. (pp. 37-38). Thousand Oaks, CA: SAGE Publications, Inc. http://dx.doi. org/10.4135/9781412963909.n20

Dritschel, B., Kao, C.M., Astell, A., Neufeind, J. \& Lai, T.-J. (2011). How are depression and autobiographical memory retrieval related to culture? Journal of Abnormal Psychology, 120(4), 96974. doi:10.1037/a0025293 
Flick, U. (2004). Introducción a la investigación cualitativa. Madrid: Morata.

Hernández Sampieri, F., Fernández Collado, C. \& Baptista, L. P. (2006). Metodología de la Investigación. Buenos Aires: Editorial de Belgrano.

Klein, O., Pieruci, S., Marchal, C., Alarcón-Henríquez, A. \& Licata, L. (2010). "It had to happen": Individual memory biases and collective memory. Revista de Psicología,28(1), 175-198.

Krause, M. (1995). La investigación cualitativa: un campo de posibilidades y desafíos. Revista Temas de Educación, 7, 19-40.

Kuyken, W. \& Moulds, M.L. (2009). Remembering as an observer: how is autobiographical memory retrieval vantage perspective linked to depression? Memory (Hove, England), 17(6), 624-34. http://doi.org/10.1080/09658210902984526

Lasa, L., Ayuso-Mateos, J. L., Vázquez-Barquero, J. L., Díez-Manrique, F.J. \& Dowrick, C.F. (2000). Use of the Beck Depression Inventory to screen for depression in the general population: preliminary analysis. Journal of Affective Disorders, 57, 261-265. https://doi.org/10.1016/S0165-0327(99)00088-9

Leiderman, E.A., Vázquez, G. H., Lolich, M., Baldessarini, R. (2012). Depression: Point-prevalence and sociodemographic correlates in a Buenos Aires community sample. Journal of Affective disorders, 136(3), 1154-1158. https://doi.org/10.1016/j.jad.2011.09.032 Lolich, M. \& Azzollini, S. (2012). Instrumentos de evaluación de la memoria autobiográfica y sus dimensiones fenomenológicas. Acta Psiquiátrica y Psicológica de América Latina, 58, 256-269.

Miró, M.T., Perestelo-Pérez, L., Pérez, J., Rivero, A., González, M., de la Fuente, J.A. \& Serrano, P. (2011). Eficacia de los tratamientos basados en Mindfulness para los trastornos de ansiedad y depresión: una revisión sistemática. Revista de Psicopatología y Psicología Clínica, 16(1), 1-16. https://doi.org/10.5944/rppc. vol.16.num.1.2011.10347

Montebarocci, O., Luchetti, M. \& Sutin, A. R. (2014). Age, memory type, and the phenomenology of autobiographical memory: 
findings from an Italian sample. Memory (Hove, England), 22(3), 295-306. doi:10.1080/09658211.2013.786093

Mosoco, M. (2014). Naturaleza de las emociones positivas en la evaluación de la Depresión: una nueva visión en psicometría. Revista de Psicología, 32(2), 202-327.

Muller, F. \& Bermejo, F. (2013). Las fuentes de la memoria colectiva: los recuerdos vividos e históricos. Revista de Psicología, 31(2), 247-264.

Mejía Navarrete, J. (2000). El muestreo en la investigación cualitativa. Investigaciones Sociales, 5, 166-180.

Rubin, D.C., Schrauf, R. W. \& Greenberg, D.L. (2003). Belief and recollection of autobiographical memories. Memory \& Cognition, 31(6), 887-901. https://doi.org/10.3758/BF03196443

Strauss, A. \& Corbin, J. (1998). Basics of qualitative research: Techniques and procedures for developing grounded theory ( $2^{\mathrm{da}} \mathrm{ed}$.). Thousand Oaks, CA: Sage.

Schaefer, A. \& Philippot, P. (2005). Selective effects of emotion on the phenomenal characteristics of autobiographical memories. Memory, 13(2), 148-60. https://doi.org/10.1080/09658210344000648

Singer, J. A. \& Salovey, P. (1993). The remembered self: Emotion and memory in personality. New York: Free Press.

Sumner, J.A., Griffith, J.W. \& Mineka, S. (2010). Overgeneral autobiographical memory as a predictor of the course of depression: a meta-analysis. Behaviour Research and Therapy, 48(7), 614-25. doi:10.1016/j.brat.2010.03.013

Sutin,A. R. \&Robins, R. W.(2007).Phenomenologyofautobiographical memories: the memory experiences questionnaire. Memory, 15(4), 390-411. doi:10.1080/09658210701256654

Sutin, A. R., Costa, P.T., Wethington, E. \& Eaton, W. (2010). Perceptions of stressful life events as turning points are associated with self-rated health and psychological distress. Anxiety, Stress, and Coping, 23(5), 479-492. https://doi.org/ 10.1080/10615800903552015

Thomsen, D. K., Schnieber, A. \& Olesen, M.H. (2011). Rumination is associated with the phenomenal characteristics of 
autobiographical memories and future scenarios. Memory, 19(6), 574-84. doi:10.1080/09658211.2011.591533

Tulving, E. (2002). Episodic memory: from mind to brain. Annual Review of Psychology, 53, 1-25. https://doi.org/10.1146/annurev. psych.53.100901.135114

Watkins, E. (2008). Constructive and unconstructive repetitive thought. Psychological Bulletin, 134(2), 163-206. doi:10.1037/00332909.134.2.163

Watkins, E. \& Teasdale, J. D. (2004). Adaptive and maladaptive selffocus in depression. Journal of Affective Disorders, 82(1), 1-8. doi:10.1016/j.jad.2003.10.006

Watkins, E., Moberly, N.J. \& Moulds, M.L. (2008). Processing mode causally influences emotional reactivity: distinct effects of abstract versus concrete construal on emotional response. Emotion, 8(3), 364-378. doi:10.1037/1528-3542.8.3.364

Werner-Seidler, A. \& Moulds, M.L. (2011a). Autobiographical memory characteristics in depression vulnerability: formerly depressed individuals recall less vivid positive memories. Cognition \& Emotion, 25(6), 1087-1103. doi:10.1080/026999 31.2010.531007

Werner-Seidler, A. \& Moulds, M.L. (2011b). Mood repair and processing mode in depression. Emotion, 12(3), 470-478. https://doi.org/10.1037/a0025984

Williams, J.M.G., Barnhofer, T., Crane, C., Herman, D., Raes, F., Watkins, E. \& Dalgleish, T. (2007). Autobiographical memory specificity and emotional disorder. Psychological Bulletin, 133(1), 122-48. doi:10.1037/0033-2909.133.1.122

Williams, J. M. G., Teasdale, J. D., Segal, Z.V. \& Soulsby, J. (2000). Mindfulness-based cognitive therapy reduces overgeneral autobiographical memory in formerly depressed patients. Journal of Abnormal Psychology, 109(1), 150-155. doi:10.1037//0021843X.109.1.150

Recibido: 18 de diciembre, 2015

Revisado: 20 de mayo, 2016 Aceptado: 17 de junio, 2016 


\section{Anexo I: Modelo de consentimiento informado utilizado durante el abordaje cualitativo}

Dentro de un Proyecto titulado "Dimensiones fenomenológicas en la evocación de recuerdos autobiográficos significativos: perfil diferencial en individuos con y sin trastorno depresivo mayor", la licenciada en Psicología María Lolich se encuentra realizando una investigación sobre las características principales de los distintos recuerdos personales que manifiestan las personas adultas.

Puntualmente dicha investigación busca poder identificar los aspectos más importantes presentes en la experiencia de recordar distintos episodios de vida, en personas que presentan o no, síntomas emocionales.

Si usted accede a participar, la Lic. Lolich le administrará dos cuestionarios:

1) Una escala que evalúa presencia de sintomatología depresiva (Inventario de Depresión de Beck) donde las respuestas serán registradas por escrito

2) Se le solicitará además, que haga memoria de un momento del pasado que para usted sea importante. A continuación se le realizarán una serie de preguntas en relación a dicho recuerdo autobiográfico. Las respuestas serán registradas mediante un grabador de voz.

A partir de los datos brindados por usted y por otros participantes se espera que los resultados derivados de la presente investigación puedan aportar mayor conocimiento al fenómeno del malestar emocional y su relación con el funcionamiento de la memoria. Además se espera que los resultados alcanzados puedan ser utilizados en el desarrollo de intervenciones clínicas que permitan mejorar los tratamientos psicoterapéuticos de la depresión.

Durante el presente estudio se respetaran las declaraciones internacionales relativas a la Declaración de Helsinki (Seúl, octubre 2008) 
y la Normativa al respecto de la Asociación Médica Argentina, en su Código de ética.

En caso de que durante el estudio se tenga información, fehaciente, fundamentada, de la falta del cumplimiento de lo estipulado en el mismo, como así no se proteja al paciente, el Comité de ética podrá suspender dicho estudio, previa aclaración y solicitud al Investigador principal y discusión

El presente estudio no implica riesgos de consideración para su salud ni para la de terceros, ni a corto ni a largo plazo. De todas maneras, de sentirse usted afectado como resultado de haber participado en esta investigación, usted podrá consultar a la investigadora en la dirección de contacto que figura al principio de cada una de las hojas de este consentimiento informado. Además, de resultar necesario usted podrá ser derivado para recibir la atención correspondiente por los profesionales del Servicio de Salud Mental del Hospital.

Tenga en cuenta que NO EXISTEN RESPUESTAS CORRECTAS O INCORRECTAS.

En cualquier momento usted es libre de suspender su participación en el estudio si así lo desea o requiere. Esto no traerá ningún tipo de perjuicio en su atención.

Una vez concluida la evaluación, la investigadora le informará los resultados obtenidos. Además, ante cualquier duda usted puede consultar a la investigadora y posteriormente también podrá hacer un seguimiento del desarrollo y resultados finales de dicho proyecto a la dirección de contacto que se brinda a continuación: Lic. María Lolich, mail: lolichm@yahoo.com.ar; de lunes a viernes de 10 a 18 hs. Todo mensaje recibido en dicha dirección será respondido a la mayor brevedad.

Por este medio solicitamos su autorización para que los datos recogidos en la siguiente evaluación puedan ser utilizados para la investigación de referencia. Todos sus datos personales serán confidenciales. De aceptar participar, la información por usted brindada será identificada por un código, el cual será otorgado a sus respuestas y asegurará 
su anonimato. Dichos datos podrán ser utilizados posteriormente, manteniendo siempre la confidencialidad, en futuros estudios, eventos científicos, publicaciones, etc.

Por tanto, la información que UD. brinde es ABSOLUTAMENTE CONFIDENCIAL, quedando completamente resguardados su identidad y los datos brindados.

Si está de acuerdo le pedimos que firme el consentimiento que aparece a continuación.

GRACIAS POR SU VALIOSA COLABORACIÓN. 


\section{Anexo II: Ejes de las entrevistas en profundidad}

- ¿De los distintos recuerdos que puedas tener sobre momentos de tu vida, tratando de ser específico ¿podrías contarme todo lo que recuerdes sobre algún momento puntual, de particular importancia para vos?

- ¿Recordás la secuencia completa de cómo se fue dando todo el evento o el orden en el que se dieron los hechos se te presenta de a partes? ¿Es confuso el orden?

- ¿Recordás que había pasado antes y/o que pasó después?

- ¿Recordás si había otras personas? ¿Recordás que hacías vos y/o los otros?

- ¿Recordás los olores? ¿Recordás los sonidos? ¿Recordás algún sabor?

- ¿Recordás si sentiste alguna sensación táctil, visceral o de dolor en particular?

- ¿Recordás imágenes? ¿Qué detalles visuales podrías mencionar?

- ¿Recordás el evento en colores o en blanco y negro?

- ¿La imagen actual del recuerdo se te presenta más como si vos lo estuvieras viendo desde afuera (como lo vería un observador externo) o se te presenta como si lo estuvieras viviendo vos mismo nuevamente?

- ¿Recordás donde ocurrió?

- ¿En cuales circunstancias o momentos soles hacer memoria de este recuerdo?

- ¿Recordás el día en el que ocurrió?

- ¿Para poder localizar temporalmente este recuerdo tuviste que buscar en tu "mente" referencias personales que te ayudaran a poder fechar el recuerdo (por ejemplo: esto tiene que haber 
pasado en tal momento porque después pasó tal o cual cosa) o la fecha forma parte del recuerdo (fue más «automática», supiste casi de inmediato y sin mucho esfuerzo la fecha del suceso)?

- ¿Recordás el momento del día?

- ¿Recordás si sentiste alguna emoción en particular? ¿Cuáles?

- ¿Las experimentas en este momento? ¿cuáles emociones experimentas ahora?

- ¿Sentís que tenés que hacer esfuerzo para recordar estos detalles o los recordás fácilmente como de modo espontáneo?

- ¿Por qué dirías que este recuerdo es importante para vos?

- ¿Con cuanta frecuencia dirías que recordás o pensas en este recuerdo?

- ¿Contás con fotografías, filmaciones o algún registro de este recuerdo?

- ¿Hablas con amigos o familiares de este recuerdo? ¿con cuanta frecuencia aproximadamente (¿más o menos de 5 veces?)?

- ¿soles compartir este recuerdo con otras personas? ¿en cuales circunstancias?

- ¿Vincularías a este recuerdo con algún momento previo y/o posterior de tu vida?

Donde se considere necesario se le solicitará al participante si pueden especificar la nitidez o claridad de sus referencias y se buscará precisión respecto a la diferencia entre re-experimentar lo relatado o "solo saberlo" 